\title{
Vulvar Schistosomiasis: An Infrequent Localization of the Female Genital Schistosomiasis
}

\author{
Patrice Bourée $^{1 *}$, Clarence de Belilovsky ${ }^{1}$, Françoise Plantier ${ }^{2}$, Sophie Berville-Levy ${ }^{3}$ \\ ${ }^{1}$ Alfred Fournier Institute, Paris, France \\ ${ }^{2}$ Department of Pathology, Cochin Hospital, Paris, France \\ ${ }^{3}$ Department of Gynecology, Cochin Hospital, Paris, France
}

\begin{abstract}
Female genital schistosomiasis (FGS) is frequent in sub-Saharian Africa, Madagascar, and the Middle East, with localization in all organs of the reproductive tract, which causes many problems. However, vulvar localization of this disease is uncommon. The patient was a young woman of 25 years old with a complaint of a mass in the right labia minora. After the tumor removal, pathology examination revealed inflammatory granuloma with eggs of Schistosoma haematobium. The patient has never travelled to an endemic tropical area but has bathed in a contaminated river in Corsica, an island located in the south of France. The diagnosis of vulvar schistosomiasis can only be confirmed by biopsy of the lesion.

Keywords: Female genital schistosomiasis, Schistosoma haematobium, Vulva, Corsica
\end{abstract}

Received: June 7, 2020, Accepted: August 24, 2020, ePublished: October 14, 2020

\section{Introduction}

Urinary schistosomiasis is a very common disease in tropical African countries. Female genital schistosomiasis (FGS), whose prevalence is estimated to be $30 \%-50 \%$ in endemic areas, occurs when ova or adults of Schistosoma haematobium are located in the female genital system, mostly in ovaries (1), Fallopian tubes, uterus, and vagina. However, vulval localization is rarely observed (2) as this case report.

\section{Case Presentation}

A 25-year-old woman, with no medical history, presented with the complaint of vulvar pruritus with local burning sensation for several months. The gynecological examination revealed the presence of a small firm and tender swelling on the right labia minora (Figure 1). The biopsy revealed an inflammatory granuloma comprising of lympho-plasma cells, eosinophils and giant cells, as well as S. haematobium eggs in the center (Figures 2A and $2 \mathrm{~B}$ ). There were no other lesions and her clinical and laboratory results were normal, including parasitological examinations of stool and urine. Bilharzia serology was weakly positive (Elisa: 49; Western blot: proteins $\mathrm{p} 8$ and p24). She had no history of travel to Africa, Madagascar (3), or the Middle East. However, a few years earlier, she traveled to Corsica, a small island in the south of France and had bathed in a river with her husband. The husband presented with hematuria. He was diagnosed with urinary schistosomiasis and treated. After treatment with praziquantel and surgical removal of the lesion, the symptoms disappeared.

\section{Discussion}

Corsica is a very beautiful island in the south of France, with a very pleasant temperate climate, and it is not an endemic area for bilharzia. However, a few years ago, the river was contaminated with a Senegalese strain of $S$. haematobium. However, since there were Bulinidae-type molluscs in the river, the infestation quickly spread to this river, which caused a small local epidemic of bilharzia $(4,5)$. The river has since been treated and schistosomiasis has disappeared.

The health consequences of FGS are infertility, ectopic pregnancy, and miscarriage with negative impacts on families and societies. Cervical and vaginal lesions are common, with spontaneous abortions, postcoital bleeding, dyspareunia, vaginal discharges, pelvic pains, and genital itch (6). Moreover, it facilitates the transmission of sexually transmitted infections, such as HPV or HIV. However, it is interesting to note that other sexually transmitted diseases do not correlate with bilharzia. In a study, 2 villages in Madagascar, where the prevalence of sexually transmitted diseases is identical, were compared and it was revealed that the prevalence of FGS was reported to be $75 \%$ in one village and it was only $5 \%$ in the other (7). 


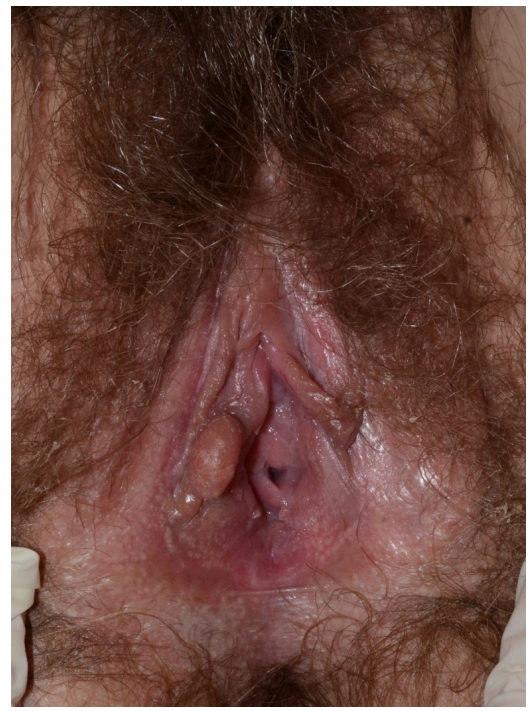

Figure 1. Tumor of the Right Labia.

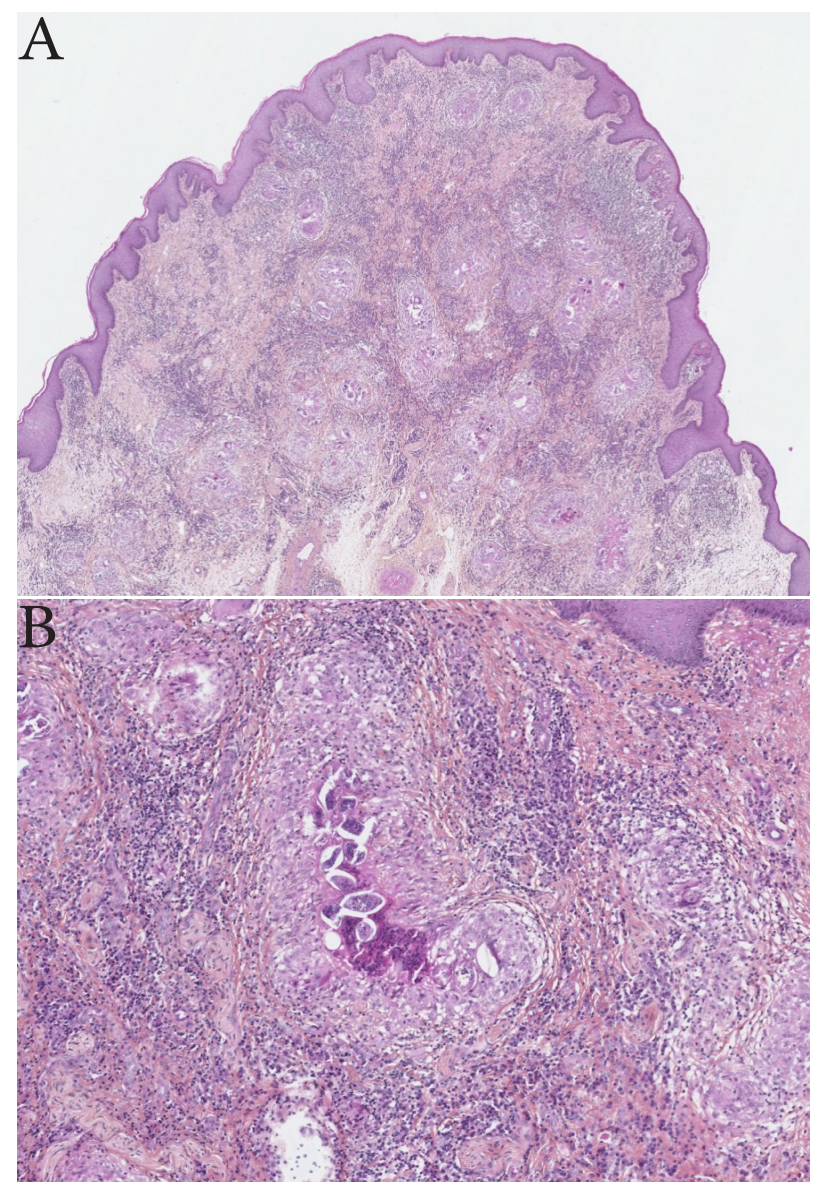

Figure 2. (A) Biopsy of the Labia: Numerous Inflammatory Granulomas with Schistosoma haematobium Eggs (Coloration with HES). (B) Several Schistosoma Haematobium Eggs in an Inflammatory Granuloma (Coloration with HES).

The prevalence of urinary schistosomiasis decreased with increasing age, but FGS prevalence remained stable, according to the age group. The most frequently reported manifestations are vaginal itching (63\%) and vaginal discharge (56\%). In a study on 398 women with FGS in Ghana, cervical lesions and vaginal discharges were frequent (Table 1). S. haematobium eggs can be found in the Fallopian tubes (16\%), cervix (42\%), vagina, vulva, and clitoris (21\%) (8).

A study in South Africa including 139 gynecological examinations revealed that $79 \%$ of bilharzia infestation caused not only by $S$. haematobium throughout the genital area, including the placenta but also by S. mansoni in the Fallopian tubes and vulva (9). Another study in Tanzania on 38400 patients found 170 cases of FGS with bilharzia eggs in the cervix (101 cases), vagina and vulva (22 cases), and Fallopian tubes (15 cases) (10); however, the relationship between FGS and cervix cancer was not demonstrated (11). Most of the cases are asymptomatic. In the other cases, lesions are variable including nodules, cysts, warts, papilloma. Vulvar localization is rare at all ages (12), but it is mostly seen in young women, while cervical lesions are more frequent over the age of 40 (Table 2) (13). Genital damage usually occurs during the infection but it is sometimes diagnosed long after its occurrence, as the case of a little girl infected at the age of 4 but it was not diagnosed until the appearance of a tumor in the labia minora at the age of 20 (14).

The diagnosis of genital schistosomiasis is confirmed by a biopsy from the genitals, showing the presence of eggs not only in the ovaries, uterus, vagina, and vulva but

Table 1. Clinical Lesions Observed in A Survey in Ghana (8)

\begin{tabular}{lcc}
\hline Organ & Lesion & Positive \\
\hline & Ulcer & $0.8 \%$ \\
Vagina-vulva & Oedema & $0.8 \%$ \\
$(398$ women $)$ & Erosion & $2 \%$ \\
& Discharge & $33.4 \%$ \\
Cervix & Erythematous & $18.8 \%$ \\
$(388$ women $)$ & Punctuate & $1,6 \%$ \\
& Sandy patches & $3,1 \%$ \\
\hline
\end{tabular}

Table 2. Number of Examined Organs with Schistosoma haematobium Eggs in Tanzania (13)

\begin{tabular}{lcccc}
\hline \multirow{2}{*}{ Organ } & \multicolumn{4}{c}{ Age (y) } \\
\cline { 2 - 5 } Cervix & $\mathbf{5 - 1 9}$ & $\mathbf{2 0 - 2 9}$ & $\mathbf{3 0 - 3 9}$ & $\mathbf{4 0 - 6 0}$ \\
Uterus & 2 & 15 & 18 & 28 \\
Ovary & 1 & 5 & 5 & 7 \\
Fallopian tubes & - & 5 & 7 & 2 \\
Vagina/vulva & - & 2 & 2 & 1 \\
Labia & 5 & 1 & - & - \\
Perineum & 2 & - & - & - \\
Peritoneum & - & - & - & - \\
Total & 10 & 32 & 4 & - \\
\hline
\end{tabular}


also in vaginal secretions (15). In these genital locations, the parasitological examinations of urine and stool can be negative. Bilharzia serology may also be negative in old infestations.

Complications of urogenital lesions in bilharzia can be urinary (bladder fibrosis, tumors, and hydronephrosis), gynecological (secondary infertility and tubal stenosis), or infectious (exacerbation of HIV infection). Indeed, on the one hand, genital schistosomiasis erodes the mucous membranes and causes their bleeding at the slightest contact and on the other hand bilharzia granulomas contain CD4 cells and macrophages which facilitate the intracellular penetration of HIV. For example, in Zimbabwe, of 520 women infected with HIV, $41 \%$ were infected with S. haematobium and only $21 \%$ were among non-infected women (16).

Praziquantel is the recommended treatment against different forms of bilharzia, including genital schistosomiasis. However, sometimes surgery is needed in case of vulvar lesions to restore the appearance of the vulva.

\section{Conclusion}

Bilharziasis should be one of the etiologies to look for in papulonodular or vegetative lesions of the vulva, especially in patients who have a history of a stay, even a short one, in an endemic zone.

\section{Informed Consent}

Written informed consent was obtained form the patient for publication of this report.

\section{Conflict of Interests}

The authors declare that they have no competing interests.

\section{References}

1. Poggensee G, Feldmeier H. Female genital schistosomiasis: facts and hypotheses. Acta Trop. 2001;79(3):193-210. doi:10.1016/s0001-706x(01)00086-9

2. McKee PH, Wright E, Hutt MS. Vulval schistosomiasis. Clin Exp Dermatol. 1983;8(2):189-194. doi:10.1111/j.1365-2230.1983.tb01764.x

3. Gras C, Andre JL, Pescarrere JL, Normand P, Barabe P. La bilharziose vulvaire: (a propos d'une observation). Med Trop. 1980;40(3):335-338.

4. Bourée P, Paugam A. La bilharziose est arrivée en Corse!. Option/Bio. 2014;25(517):13-16

5. Berry A, Moné $\mathrm{H}$, Iriart $\mathrm{X}$, et al. Schistosomiasis haematobium, Corsica, France. Emerg Infect Dis. 2014;20(9):1595-1597. doi:10.3201/eid2009.140928

6. Bourée P. Les parasitoses génito-urinaires. Encycl Med Chir Urol. 2017; 18-231:17.

7. Leutscher P, Raharisolo C, Pecarrere JL, et al. Schistosoma haematobium induced lesions in the female genital tract in a village in Madagascar. Acta Trop. 1997;66(1):27-33. doi:10.1016/s0001-706x(97)00673-6

8. Yirenya-Tawiah D, Amoah C, Apea-Kubi KA, et al. A survey of female genital schistosomiasis of the lower reproductive tract in the volta basin of Ghana. Ghana Med J. 2011;45(1):16-21. doi:10.4314/gmj.v45i1.68917

9. Lambertucci JR, Voieta I, De Brot M. Vulvar schistosomiasis mansoni. Rev Soc Bras Med Trop. 2008;41(4):435-436. doi:10.1590/s0037-86822008000400026

10. Hegertun IE, Sulheim Gundersen KM, Kleppa E, et al. S. haematobium as a common cause of genital morbidity in girls: a cross-sectional study of children in South Africa. PLoS Negl Trop Dis. 2013;7(3):e2104. doi:10.1371/journal. pntd.0002104

11. van Raalte JA, Venkataramaiah NR, Shaba JK. Bilharziasis of the female genital tract in Tanzania. East Afr Med J. 1981;58(7):543-547.

12. Faye $\mathrm{O}$, Darie $\mathrm{H}$, Keita $S, \mathrm{~N}^{\prime}$ diaye $H T$, Traoré $A K$, Mahé $A$. Complications vulvaires de la schistosomose uro-génitale: étude de 8 cas à Ségou, Mali. Bull Soc Pathol Exot. 2006;99(2):96-98.

13. Swai B, Poggensee G, Mtweve S, Krantz I. Female genital schistosomiasis as an evidence of a neglected cause for reproductive ill-health: a retrospective histopathological study from Tanzania. BMC Infect Dis. 2006;6:134. doi:10.1186/1471-2334-6-134

14. Fall PA, Berthe $\mathrm{H}$, Diao $\mathrm{B}$, et al. Localisation vulvaire de la bilharziose. Prog Urol. 2008;18(5):327-329.

15. Sturt AS, Webb EL, Phiri CR, et al. Genital self-sampling compared with cervicovaginal lavage for the diagnosis of female genital schistosomiasis in Zambian women: the BILHIV study. PLoS Negl Trop Dis. 2020;14(7):e0008337. doi:10.1371/journal.pntd.0008337

16. Kjetland EF, Ndhlovu PD, Gomo E, et al. Association between genital schistosomiasis and HIV in rural Zimbabwean women. AIDS. 2006;20(4):593-600. doi:10.1097/01. aids.0000210614.45212.0a

(C) 2020 The Author(s); This is an open-access article distributed under the terms of the Creative Commons Attribution License (http:// creativecommons.org/licenses/by/4.0), which permits unrestricted use, distribution, and reproduction in any medium, provided the original work is properly cited. 